\title{
Increased myocardial dysfunction, dyssynchrony, and epicardial fat across the lifespan in healthy males
}

Edward Crendal ${ }^{1,2^{*}}$, Fred Dutheil ${ }^{1,3,4}$, Geraldine Naughton ${ }^{1}$, Tracey McDonald ${ }^{1}$ and Philippe Obert ${ }^{1,2}$

\begin{abstract}
Background: Evaluation of sensitive myocardial mechanics with speckle tracking echocardiography (STE) across the lifespan may reveal early indicators of cardiovascular disease (CVD) risk. Epicardial adipose tissue (EAT) and left ventricular (LV) myocardial dyssynchrony; subclinical risk-factors of CVD, are of particular clinical interest. However, the evolution of EAT and LV-dyssynchrony across the lifespan, and their influence on myocardial dysfunction remains unclear. We aimed to establish a profile of the healthy aging-heart using conventional, tissue-Doppler imaging (TDI) and speckle-tracking echocardiography (STE), while also exploring underlying contributions from EAT and LV-dyssynchrony towards LV myocardial mechanics, independent of blood biology.

Methods: Healthy males aged 19-94 years were recruited through University-wide advertisements in Victoria and New-South Wales, Australia. Following strict exclusion criteria, basic clinical and comprehensive echocardiographic profiles (conventional, TDI and STE) were established. LV-dyssynchrony was calculated from the maximum-delay of time-to-peak velocity/strain in the four LV-annulus sites (TDI), and six LV-segments (STE longitudinal and circumferential axes). Epicardial fat diameter was obtained from two-dimensional grey-scale images in the parasternal long-axis. Blood biological measures included glycemia, hsCRP, triglycerides, total cholesterol, high-density and low-density lipoprotein levels.
\end{abstract}

Results: Three groups of 15 were assigned to young ( $<40$ years), middle (40-65 years), and older ( $>65)$ aged categories. Five participants were excluded from STE analyses due to inadequate image quality. Decreased longitudinal strain, increased circumferential apical strain and LV twist were age-related. Moreover, independent of blood biology, significant increases were observed across age categories for EAT (young: $2.5 \pm 0.9 \mathrm{~mm}$, middle: $3.9 \pm$ $1.0 \mathrm{~mm}$, older $5.7 \pm 2.4 \mathrm{~mm} ; \mathrm{p}<0.01$ ), longitudinal STE-dyssynchrony (young: $42 \pm 7.7 \mathrm{~ms}$, middle: $58.8 \pm 18.9 \mathrm{~ms}$, older $88.6 \pm 18.2 \mathrm{~ms} ; \mathrm{p}<0.05$ ), and circumferential-basal STE-dyssynchrony (young: $50.2 \pm 20.5 \mathrm{~ms}$, middle: $75.9 \pm 20.6 \mathrm{~ms}$, older $97.9 \pm 20.2 \mathrm{~ms} ; \mathrm{p}<0.05)$. These variables collectively explained $37 \%$ and $31 \%(\mathrm{p}<0.01)$ of longitudinal strain and LV twist, respectively.

Conclusions: This study enabled comprehensive profiling of LV mechanics at different stages of aging using sensitive echocardiographic technology. Novel findings included increased epicardial fat, and both longitudinal and circumferential LV-dyssynchrony across the healthy age groups. These factors may be key underlying contributors to myocardial dysfunction during aging, and their recognition may promote an advanced understanding of early signs of cardiovascular disease.

Keywords: Aging, Speckle tracking echocardiography, Dyssynchrony, Myocardial dysfunction, Epicardial fat

\footnotetext{
* Correspondence: edwardcrendal@gmail.com

'School of Exercise Science, Australian Catholic University, Locked Bag 4115,

Fitzroy, MDC Victoria 3065, Australia

2Laboratory of Pharm-Ecology Cardiovascular EA4278, School of Sport

Sciences and Exercise, University of Avignon, Avignon, France

Full list of author information is available at the end of the article
} 


\section{Background}

Increased life expectancy and decreased birth rates contribute to the notion of global population aging [1,2], with cardiovascular disease (CVD) remaining the primary contributor to mortality [3]. A better understanding of the healthy aging-heart may support the early prevention, and thus reduced burden, of CVD. Evidence suggests that normal aging is associated with left ventricular (LV) hypertrophy and decreased diastolic LV function, assessed with conventional and tissue Doppler imaging (TDI) echocardiography [4-6]. The use of speckle tracking echocardiography (STE) may permit more sensitive analyses of the aging-heart, through the angle-independent assessment of myocardial deformation (myocardial mechanics) in the longitudinal and circumferential axes, as well as twist mechanics [7]. Previous studies of LV myocardial mechanics across the lifespan report an age-related decrease in longitudinal deformation, as well as compensatory increases in LV twist using STE [8-13]. Meanwhile, the evolution of circumferential deformation with age remains inconclusive.

Underlying contributors to these LV changes in healthy aging populations are poorly understood. Specifically, epicardial adipose tissue (EAT), measured feasibly by echocardiography, is strongly associated with myocardial lipid content; a potentially major contributor to LV dysfunction in populations with metabolic disorders $[14,15]$. However, the influence of EAT on LV myocardial mechanics in healthy older people is unknown and warrants further attention since it may provide an early indication of CVD risk.

Furthermore, non-uniform contraction of LV myocardial walls due to declining electromechanical synchronicity (LV-dyssynchrony) may result in myocardial inefficiency [16], and could also be an underlying contributor to these age-related impairments in LV myocardial mechanics. Previous studies have found increasing circumferential [17], longitudinal and radial [18] LV-dyssynchrony with age. Nonetheless, no studies have examined the association of both longitudinal and circumferential LV-dyssynchrony with STE-derived indices of myocardial mechanics, such as LV longitudinal and circumferential strain as well as twist, in a healthy aging population.

The primary aim of this cross-sectional study was therefore to establish a comprehensive profile of LV mechanics across different age categories of healthy males, using conventional, TDI and STE echocardiography. A secondary aim was to explore how EAT and LV-dyssynchrony change with age, and quantify their underlying contribution to important measures of LV myocardial mechanics, independently of blood-biology, within this population.

\section{Methods}

\section{Population and design}

Participants provided informed consent prior to commencement of testing, and the study protocol conformed to the ethical guidelines of the 1975 Declaration of Helsinki as reflected in a prior approval by the Human Research Ethics Committee (HREC) of the Australian Catholic University, Melbourne, Australia. Volunteers were recruited through advertisements, and all participants provided informed consent. Inclusion criteria were males aged over 18 years with no maximum age limit, no prior cardiovascular disease history, diabetes mellitus, dyslipidemia, or hypertension, no routine medication, and (to avoid highly trained athletes) practising less than 10 hours per week of moderate to intense physical activity. Volunteers were screened with verbal interviews and written questionnaires. We recruited males from three age categories: younger than 40 years $(\mathrm{Y})$; 40 to 65 years $(\mathrm{M})$; and older than 65 years $(\mathrm{O})$.

\section{Clinical and biochemical parameters}

Stature, body mass, and body mass index (BMI) were recorded. Blood pressure was measured with a digital sphygmomanometer (Carescape-V100, Dinamap, General Electric technology, USA) after 15 minutes lying in the supine position. Physical activity was quantified using the International Physical Activity Questionnaire modified for elderly populations [19].

Fasted serum concentrations of glucose, triglycerides, total cholesterol, high-density lipoprotein (HDL), low-density lipoproteins (LDL), and high-sensitivity C-reactive protein (hsCRP) were analysed at a clinical pathology laboratory (Melbourne Pathology, Australia).

\section{Conventional echocardiography}

Participants underwent transthoracic echocardiogram and electrocardiogram examination by the same experienced operator, following standard recommendations [20]. Images and cine-loops were obtained using an equipment pack (Vivid-i, General Electric, Milwaukee, WI, USA) and a $3.5-\mathrm{MHz}$ probe. Images were digitally recorded for subsequent offline analysis with dedicated software (EchoPAC PC, Version 5, General Electric Healthcare). Each variable was measured on an average of three consecutive cardiac cycles. M-Mode measurements were obtained in the parasternal long-axis view. Left atrial (LA) and LV dimensions were measured at end-diastole and end-systole. LV mass was calculated by the Devereux formula, and indexed for height [21], and LV ejection fraction was derived from semiautomatic quantification of LV volumes, using STE. Pulsed-Doppler LV transmitral blood velocity, including early (E) and atrial (A) waves, were measured in the apical four-chamber view. Isovolumic relaxation time was measured by pulsed Doppler in the apical five-chamber view, along with aortic ejection velocity. Spectral pulsed-TDI measures of myocardial systolic $\left(\mathrm{S}_{\mathrm{m}}\right)$, early diastolic $\left(\mathrm{E}_{\mathrm{m}}\right)$, and late diastolic $\left(\mathrm{A}_{\mathrm{m}}\right)$ velocities were assessed at the mitral annulus of the LV, in apical four (septal and lateral) 
and two (anterior and inferior) chamber views. The $\mathrm{E} / \mathrm{E}_{\mathrm{m}}$ ratio, recorded from the mitral annulus lateral wall, was used as an index of LV filling pressure. The tricuspid annular plane systolic excursion (TAPSE) and TDI $\mathrm{S}_{\mathrm{m}}$ velocity were also assessed on the lateral (free) wall of the right ventricle. EAT diameter was manually measured on the free wall of the right ventricle from the two-dimensional grey-scale image in the parasternal long-axis view, as previously described [22].

\section{Speckle tracking echocardiography}

The STE mode of two-dimensional strain imaging was used to measure more sensitive myocardial mechanics. Offline analyses were performed in the circumferential axis at the base, papillary-muscle level, and apex of the LV (parasternal short-axis), as well as in the longitudinal axis (apical four-chamber view), using software described above. In the respective B-mode two-dimensional greyscale cine-loops, a region of interest was manually placed along the endocardial border, and automatically covered myocardial thickness to the epicardial border. Six segments were subsequently analysed in each view. Cineloops without adequate endocardial border definition, frame rate $(>60 \mathrm{~Hz})$, and image tracking were excluded from analyses. The cine-loops were animated, and LV longitudinal strain, strain rate (SR), and time to peak strain/ SR were obtained in the apical four-chamber view. Circumferential strain, SR, time to peak strain/SR, and rotation were obtained from the short-axis view at the LV base and apex. LV twist was calculated as the instantaneous difference between apical and basal rotation. To adjust all STE variables for inter-participant differences in heart rate, the time sequence was normalized to the percentage of systolic duration (i.e. 100\% at aortic valve closure) using a toolbox generated in our laboratory (Scilab 4.1) [23]. Inter and intra-observer reproducibility were estimated in three views from 10 randomly selected participants, and the coefficient of variations were $5.4 \%$ and $5.1 \%$, respectively for strain, and $10.1 \%$ and $7.9 \%$, respectively for twist.

\section{Left ventricular dyssynchrony}

TDI LV-dyssynchrony was measured by recording time taken from the start of QRS complex to peak $S_{m}$ (systolic dyssynchrony) or peak $E_{m}$ (diastolic dyssynchrony) at the annulus of the septal and lateral walls (apical four-chamber view), and inferior and anterior walls (apical two-chamber view). For STE LV-dyssynchrony, time taken from the start of QRS to peak strain in the six LV segments was measured in both longitudinal (apical 4-chamber) and circumferential (parasternal short-axis basal and apical levels) axes. LV-dyssynchrony was evaluated using the maximum delay technique in the four (TDI) or six (STE) segments. This modality of measuring LV-dyssynchrony is more sensitive than the $\mathrm{Yu}$ index or opposing wall delay [24]. Clinical diagnosis was made if maximum delay was greater than $65 \mathrm{~ms}$ [25] and $100 \mathrm{~ms}$ [26] for TDI and STE, respectively. For STE dyssynchrony, inter and intra-observer reproducibility (coefficient of variation) were $9.3 \%$ and $10.2 \%$, respectively.

\section{Statistical analyses}

It was predicted that a minimum of 13 participants in each population sub-group ( $\mathrm{Y}, \mathrm{M}$, and $\mathrm{O}$ ) would allow detection of a significant difference if the mean of the major cardiac variables was between 1 and 1.25 standard deviations higher than the mean value between the groups $(80 \%$ power; $\mathrm{p}<$ 0.05) [26]. After verifying Gaussian distribution, clinical, biological, and echocardiographic data were presented as means (standard deviation). One-way analysis of variance (ANOVA) with Tukey's post-hoc tests were used to assess differences between $\mathrm{Y}, \mathrm{M}$, and $\mathrm{O}$ groups. In order to preclude outliers, we excluded data with values beyond two standard deviations of the group mean [27]. Pearson's $r$ correlation analyses were performed between age, cardiac variables, and blood biology. Univariate analysis of covariance (ANCOVA) was performed to test the strength of the relationships between LV-dyssynchrony and age; after the effects of glucose, total cholesterol and hsCRP were controlled. A stepwise linear regression model assessed the predictive role of LV-dyssynchrony on major indices of myocardial mechanics (LV twist and longitudinal strain). Analyses were performed using SPSS Version 16.0 for windows (SPSS Inc), with statistical significance set at $\mathrm{p}<0.05$.

\section{Results}

\section{Participants}

Participant recruitment is described in Figure 1. Fortyfive healthy males took part in the study. Fifteen participants per group were assessed using conventional, TDI, and longitudinal STE echocardiography. One (Y), two $(\mathrm{M})$ and two $(\mathrm{O})$ participants were excluded for circumferential STE analysis due to insufficient image quality. Normal sinus rhythm, with no widening of QRS morphology was present in all participants.

\section{Clinical and biochemical parameters}

Mean ages of participants were $25.7 \pm 6.1(\mathrm{Y}), 49.3 \pm 8.8$ $(\mathrm{M})$ and $77.7 \pm 9.8(\mathrm{O})$. Participant age ranged from 19 to 94 years. Age groups did not differ in body mass, BMI, systolic and diastolic blood pressure, hsCRP, triglycerides, HDL, LDL, total cholesterol, and glucose. Stature was lower in $\mathrm{O}$ than $\mathrm{M}$ and $\mathrm{Y}$ groups $(\mathrm{p}<0.05)$ (Table 1$)$.

\section{Conventional echocardiographic and TDI parameters}

Results from $L V$ remodeling (Table 2) showed only interventricular septum thickness and relative wall thickness 


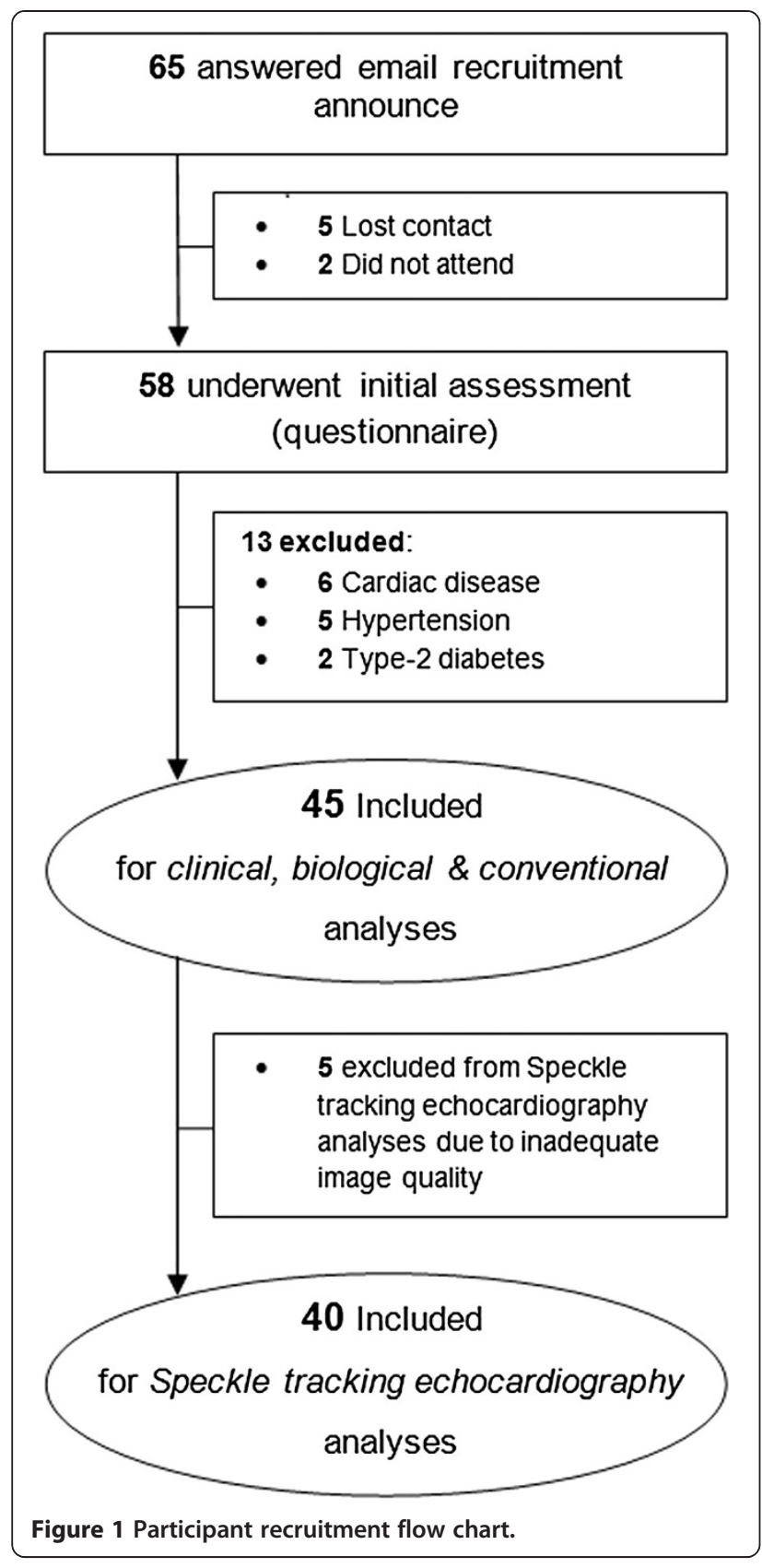

(RWT) were greater in $\mathrm{O}$ than $\mathrm{Y}(\mathrm{p}<0.05)$, but neither differed from $M$. RWT was also greater in $M$ than $Y$ $(\mathrm{p}<0.05)$.

Among results from functional $L V$ parameters, no group differences were observed in systolic function (LV ejection fraction and $\mathrm{S}_{\mathrm{m}}$ ). However, diastolic function was impaired across the age groups. E/A ratio was lower in $\mathrm{O}$ than both $M$ and $Y(p<0.001)$, without differences between $M$ and $\mathrm{Y}$. $\mathrm{E}_{\mathrm{m}}$ was lower in both $\mathrm{O}$ and $\mathrm{M}$ than $\mathrm{Y}(\mathrm{p}<0.001)$, without differences between $\mathrm{O}$ and $\mathrm{M}$. Deceleration time of $\mathrm{E}$ and LV filling pressure $\left(\mathrm{E} / \mathrm{E}_{\mathrm{m}}\right)$ were greater in $\mathrm{O}$ than $\mathrm{Y}$ $(p<0.05)$, but not different from M. Isovolumic relaxation time was more prolonged in both $\mathrm{O}$ and $\mathrm{M}$ than $\mathrm{Y}(\mathrm{p}<$ 0.05 ), but $\mathrm{O}$ and $\mathrm{M}$ were similar.

Results from the $R V$ analyses (Table 2) showed no inter-group differences for tricuspid annular plane systolic excursion TAPSE. However, $\mathrm{S}_{\mathrm{m}}$ was lower in both $\mathrm{O}$ and $\mathrm{M}$ than $\mathrm{Y}(\mathrm{p}<0.05)$, without differences between $\mathrm{O}$ and $\mathrm{M}$. EAT diameter was greater in $\mathrm{O}$ than both $M$ and $Y(p<0.001)$, while $M$ was also greater than $\mathrm{Y}(\mathrm{p}<0.001)$.

\section{Speckle tracking echocardiographic parameters}

For longitudinal strain and diastolic SR (Table 3), O was lower than $\mathrm{M}$ and $\mathrm{Y}$, respectively $(\mathrm{p}<0.001$ and $\mathrm{p}<0.05)$, while no differences were observed between $M$ and $Y$. Longitudinal systolic SR was unaltered by age. Despite no between group differences for basal circumferential characteristics; apical circumferential strain and systolic SR were greater in $\mathrm{O}$ and $\mathrm{M}$ than $\mathrm{Y}(\mathrm{p}<0.05)$. However, apical circumferential strain was similar in $\mathrm{O}$ and $\mathrm{M}$. Apical circumferential diastolic SR was unaltered by age (Table 3 ). Further analyses of circumferential mechanics showed no differences across the lifespan for basal rotation. However, apical rotation was greater in $\mathrm{O}$ and $\mathrm{M}$ than $\mathrm{Y}(\mathrm{p}<0.05)$. Subsequent LV twist and untwist rates were greater in $\mathrm{O}$ than $\mathrm{Y}(\mathrm{p}<0.05)$, but not different from $\mathrm{M}$.

\section{Left ventricular dyssynchrony parameters}

Measures of LV-dyssynchrony across the age groups are presented in Figure 2. Both TDI-derived systolic and diastolic maximum delay were greater in $\mathrm{O}$ than $\mathrm{Y}(\mathrm{p}<0.05)$. TDI-derived maximum delay did not differ between $\mathrm{O}$ and $\mathrm{M}$, nor $\mathrm{M}$ and $\mathrm{Y}$. In contrast, STE-derived longitudinal maximum delay was greater in $\mathrm{O}$ than both $\mathrm{M}$ and $\mathrm{Y}$ $(\mathrm{p}<0.001)$, while also greater in $\mathrm{M}$ than $\mathrm{Y}(\mathrm{p}<0.05)$. Additionally, STE-derived circumferential maximum delay at the base was greater in $\mathrm{O}$ than both $\mathrm{M}$ and $\mathrm{Y}$ $(\mathrm{p}<0.05)$, while also greater in $\mathrm{M}$ than $\mathrm{Y}(\mathrm{p}<0.05)$. No inter-group differences existed for STE-derived circumferential maximum delay at the apex.

\section{Relationships amongst cardiac variables, age, and blood biology}

Age was significantly associated with the following cardiac variables: longitudinal STE LV-dyssynchrony $(r=0.79)$, TDI $\mathrm{E}_{\mathrm{m}}(r=0.78)$, circumferential-basal STE LV-dyssynchrony $(r=0.77)$, E/A ratio $(r=0.75)$, EAT $(r=0.73)$, LV twist $(\mathrm{r}=$ $0.68)$, and longitudinal strain $(r=0.62)$ (all p $<0.01$ ). Age was also significantly related to hsCRP $(r=0.40)$ and triglycerides $(r=0.35)$ (both $\mathrm{p}<0.05)$. Furthermore, some cardiac variables also correlated strongly with blood biology, including; apical circumferential rotation and TDI $\mathrm{A}_{\mathrm{m}}$ with total cholesterol ( $r=0.47$ and $r=0.46$, respectively), apical circumferential systolic SR with hsCRP $(r=0.42)$, TDI $\mathrm{E}_{\mathrm{m}}$ with fasting glucose $(r=0.42)$, and EAT with triglycerides 
Table 1 Clinical and biological parameters of healthy males

\begin{tabular}{|c|c|c|c|}
\hline & $\begin{array}{c}\text { Young } \\
<40 \text { years old } \\
(n=15)\end{array}$ & $\begin{array}{c}\text { Middle } \\
\text { 40-65 years old } \\
(n=15)\end{array}$ & $\begin{array}{c}\text { Older } \\
>65 \text { years old } \\
(n=15)\end{array}$ \\
\hline Age (years) & $25.7(6.1)$ & $49.3(8.8)^{* * *}$ & $77.7(9.8)^{* * * \# \# \#}$ \\
\hline Stature $(\mathrm{cm})$ & $180.5(5.4)$ & $177.9(4.9)$ & $172.6(2.3)^{*} \#$ \\
\hline Body mass (kg) & $80.2(8.9)$ & $83.1(11.7)$ & $76.7(9.3)$ \\
\hline BMI $\left(\mathrm{kg} \cdot \mathrm{m}^{-2}\right)$ & $24.6(3.0)$ & $25.9(3.5)$ & $25.7(3.0)$ \\
\hline Systolic BP (mmHg) & $124.5(8.3)$ & $125.1(9.8)$ & $122.4(11.4)$ \\
\hline Diastolic BP (mmHg) & $73.6(8.5)$ & $79.6(6.9)$ & $73.1(9.0)$ \\
\hline Fasting glucose $\left(\mathrm{mmol} . \mathrm{L}^{-1}\right)$ & $5.1(0.3)$ & $5.3(0.4)$ & $5.2(1.0)$ \\
\hline $\mathrm{HDL}\left(\mathrm{mmol.} \mathrm{L}^{-1}\right)$ & $1.4(0.2)$ & $1.5(0.5)$ & $1.3(0.2)$ \\
\hline LDL $\left(m m o l . L^{-1}\right)$ & $2.6(1.1)$ & $3.0(0.9)$ & $3.1(0.9)$ \\
\hline Total cholesterol $\left(\mathrm{mmol} . \mathrm{L}^{-1}\right)$ & $4.4(1.2)$ & $4.9(1.0)$ & $5.1(1.0)$ \\
\hline Triglycerides $\left(\mathrm{mmol.L}^{-1}\right)$ & $0.8(0.4)$ & $1.0(0.6)$ & $1.3(0.6)$ \\
\hline High sensitivity CRP $\left(\mathrm{mg} \mathrm{L}^{-1}\right)$ & $0.7(0.4)$ & $1.0(0.7)$ & $1.8(1.7)$ \\
\hline
\end{tabular}

Data are means (standard deviations). BMI: Body mass index, BP: Blood pressure, HDL: High density lipoprotein, LDL: Low density lipoprotein, CRP: C-reactive protein. *: $p<0.05$ vs. Young; ${ }^{* * *}: p<0.001$ vs. Young; $\#$ : $p<0.05$ vs. Middle; \#\#\#: $p<0.001$ vs. Middle.

$(r=0.42)$ and hsCRP $(r=0.40)$ (all $\mathrm{p}<0.05)$. After controlling for total cholesterol, fasting glucose, and hsCRP; age remained correlated to longitudinal STE LV-dyssynchrony (adjusted $r=0.72 ; \mathrm{p}<0.001$ ).

\section{Relationships between LV-dyssynchrony, EAT and indices of myocardial mechanics}

Longitudinal LV-dyssynchrony was associated with longitudinal strain $(r=0.51 ; \mathrm{p}<0.01)$ while circumferential STE LV-dyssynchrony at the base was associated with LV twist $(r=0.52 \mathrm{p}<0.05)$. Circumferential STE LVdyssynchrony at the apex was not associated with any indices of myocardial mechanics. EAT was also associated with longitudinal STE LV-dyssynchrony $(r=0.65)$, TDI $\mathrm{E}_{\mathrm{m}}(r=0.60)$, longitudinal strain $(r=0.50)$, circumferential STE LV-dyssynchrony at the base $(r=0.44)$, and LV twist $(r=0.44)$ (all $\mathrm{p}<0.01)$. A stepwise linear regression model revealed that the combination of EAT, longitudinal STE LV-dyssynchrony, and circumferential STE LV-dyssynchrony at the base explained $37 \%$ of the variability in longitudinal strain, and $31 \%$ of the variability in $\mathrm{LV}$ twist $\left(R^{2}=0.37\right.$ and 0.32 , respectively; $\left.\mathrm{p}<0.05\right)$.

\section{Discussion}

We investigated cardiac profiles in healthy males of increasing age, using conventional and STE imaging technologies. This enabled several major findings to emerge. First, we confirmed a decline in global diastolic function and longitudinal deformation, accompanied by compensatory increases in circumferential apical strain and LV twist across the three age-groups. Additionally, for the first time with echocardiography, we showed increasing EAT, as well as longitudinal and circumferential-basal LV-dyssynchrony across the three age-groups, independent of the effects of blood biology. Moreover, these three factors emerged as significant correlates and predictors of key myocardial mechanics parameters (longitudinal strain and LV twist).

\section{Rationale for elderly male population}

Previous studies of LV myocardial function and dyssynchrony in aging people have not observed individuals older than 89 years of age $[8,9,11-13,17,18,28]$. In the present study, our participants were aged up to 94 years. We demonstrated a linear increase in LV myocardial dysfunction and dyssynchrony across the three incremental age groups. Furthermore, prior studies of the aging-heart observed mixed gender populations. We present for the first time, a study of males only. Evidence suggests myocardial tissue in females is more preserved than in males throughout aging [29]. We demonstrated that restriction to a male-only population minimised standard deviations and permitted detection of significant differences between groups, with fewer individuals and with an analysis free from hormonal confounders found in mixed gender populations [28].

\section{Aging and conventional echocardiographic parameters}

The present study found mild LV hypertrophy and more impaired diastolic function in the $\mathrm{O}$ group than $\mathrm{M}$ and $\mathrm{Y}$ groups, supporting other longitudinal studies showing LV remodeling and diastolic dysfunction across the lifespan, despite preserved LV ejection fraction [4-6,30]. The fundamental mechanisms behind these changes may be due to age-associated increases in arterial blood pressure and subsequently elevated afterload [31]. However, although $E / E_{m}$ ratio (a measure of $L V$ filling pressure) was elevated 
Table 2 Conventional and tissue Doppler imaging echocardiography parameters of healthy males

\begin{tabular}{|c|c|c|c|}
\hline & $\begin{array}{c}\text { Young } \\
<40 \text { years old } \\
(n=15)\end{array}$ & $\begin{array}{c}\text { Middle } \\
\text { 40-65 years old } \\
(n=15)\end{array}$ & $\begin{array}{c}\text { Older } \\
>65 \text { years old } \\
(n=15)\end{array}$ \\
\hline \multicolumn{4}{|l|}{ LV M-Mode } \\
\hline HR (beats.min-1) & $56.8(8.1)$ & $59.1(6.0)$ & $60.6(14.1)$ \\
\hline LAD diameter (mm) & $35.7(4.6)$ & $35.6(3.9)$ & $36.3(5.5)$ \\
\hline LVED diameter (mm) & $52.9(3.7)$ & $50.0(3.5)$ & $50.3(3.5)$ \\
\hline LVES diameter (mm) & $34.9(4.0)$ & $32.1(5.3)$ & $33.7(5.6)$ \\
\hline IVSD diameter (mm) & $10.5(0.5)$ & $11.5(1.4)$ & $11.8(1.2)^{*}$ \\
\hline PWD diameter (mm) & $10.6(0.9)$ & $11.3(1.3)$ & $11.1(1.1)$ \\
\hline $\mathrm{RWT}(\mathrm{mm})$ & $0.40(0.1)$ & $0.45(0.1)^{*}$ & $0.46(0.1)^{*}$ \\
\hline LV mass (g) & $221.6(36.3)$ & $216.5(38.4)$ & $229.4(42.5)$ \\
\hline LV mass index $\left(\mathrm{g} \cdot \mathrm{m}^{-2.7}\right)$ & $44.9(6.4)$ & $45.7(7.7)$ & $52.9(9.3)^{*} \#$ \\
\hline LV ejection fraction (\%) & $63.5(5.2)$ & $64.2(6.5)$ & $63.1(6.9)$ \\
\hline \multicolumn{4}{|l|}{ LV Pulsed-Doppler } \\
\hline E velocity $\left(\mathrm{cm} \cdot \mathrm{s}^{-1}\right)$ & $75.1(13.1)$ & $67.5(9.3)$ & $62.6(14.7)^{*}$ \\
\hline A velocity $\left(\mathrm{cm} \cdot \mathrm{s}^{-1}\right)$ & $40.4(6.6)$ & $55.9(11.7)^{*}$ & $66.8(25.8)^{* * *}$ \\
\hline $\mathrm{E} / \mathrm{A}$ & $1.9(0.5)$ & $1.3(0.4)^{* * *}$ & $1.0(0.3)^{* * *}$ \\
\hline E deceleration time (ms) & $163.9(22.4)$ & $168.1(16.5)$ & $191.9(38.8)^{*}$ \\
\hline IVRT (ms) & $94.3(11.7)$ & $110.8(16.4)^{*}$ & $115.6(25.0)^{*}$ \\
\hline \multicolumn{4}{|l|}{ LV Pulsed-TDI } \\
\hline $\mathrm{E}_{\mathrm{m}}\left(\mathrm{cm} \cdot \mathrm{s}^{-1}\right)$ & $14.2(2.2)$ & $10.3(2.8)^{* * *}$ & $8.4(2.2)^{* * *}$ \\
\hline$A_{m}\left(c m \cdot s^{-1}\right)$ & $6.6(0.8)$ & $8.0(1.7)$ & $9.0(2.4)^{*}$ \\
\hline $\mathrm{S}_{\mathrm{m}}\left(\mathrm{cm} \cdot \mathrm{s}^{-1}\right)$ & $8.0(0.7)$ & $7.4(1.5)$ & $7.5(1.3)$ \\
\hline$E / E_{m}$ & $4.9(0.8)$ & $6.1(1.7)$ & $7.4(2.7)^{*}$ \\
\hline \multicolumn{4}{|l|}{ Right ventricle } \\
\hline EAT $(m m)$ & $0.25(0.09)$ & $0.39(0.10)^{*}$ & $0.57(0.24)^{* * * \#}$ \\
\hline $\mathrm{RV} S_{m}\left(\mathrm{~cm} \cdot \mathrm{s}^{-1}\right)$ & $13.6(1.7)$ & $11.2(1.5)^{*}$ & $11.7(2.2)^{*}$ \\
\hline TAPSE (mm) & $22.8(1.8)$ & $20.6(1.4)$ & $21.6(3.4)$ \\
\hline
\end{tabular}

Data are means (standard deviations). LV: Left ventricular, HR: Heart rate, LAD: Left atrial diastolic, LVED: Left ventricular end diastolic, LVES: Left ventricular end systolic, IVSD: Interventricular septum diastolic, PWD: Posterior wall diastolic, RWT: Relative wall thickness, IVRT: Isovolumic relaxation time, EAT: Epicardial adipose tissue, RV: Right ventricle, TAPSE: Tricuspid annular plane systolic excursion. *: $p<0.05$ vs. Young; ***: $p<0.001$ vs. Young; \#: $p<0.05$ vs. Middle; \#\#\#: $p<0.001$ vs. Middle.

in O participants, both systolic and diastolic arterial blood pressures were similar across the age-groups. Analysis of cardiac function at the more regional (myocardial) level was therefore justified.

\section{Aging and myocardial mechanics}

We revealed decreasing TDI-derived diastolic myocardial velocity across the age-groups, agreeing with other aging studies [32-35]. We also confirmed previous findings of preserved TDI systolic velocity across the agegroups [32,36,37], despite some conjecture in the literature $[33,38,39]$. The exclusion of hypertensive individuals in the current but not previous studies may explain this discrepancy since blood pressure strongly influences systolic function [40]. Furthermore, longitudinal deformation (strain and both systolic and diastolic SR) was impaired in older healthy males, supporting previous studies $[11,41,42]$. Most likely in response to the impaired longitudinal deformation, we observed compensatory increases in apical circumferential deformation and LV twist with age. This would help explain the observed preservation of LV ejection fraction $[11,12,36]$. Our findings agree with recent evidence establishing age-related normal values in longitudinal strain and LV torsion using three-dimensional STE [13]. The authors found an age-related decline in longitudinal function, and increased LV torsion, concluding that these results may reflect an age-related maturation of myocardial tissue.

\section{Aging and epicardial fat accumulation}

The first major novel finding from the current study was the increased EAT across the age-groups. Echocardiography- 
Table 3 Left ventricular speckle tracking echocardiography parameters of healthy males

\begin{tabular}{|c|c|c|c|}
\hline & $\begin{array}{c}\text { Young } \\
<40 \text { years old } \\
(n=14)\end{array}$ & $\begin{array}{c}\text { Middle } \\
\text { 40-65 years old } \\
(n=13)\end{array}$ & $\begin{array}{c}\text { Older } \\
>65 \text { years old } \\
(n=13) \\
\end{array}$ \\
\hline \multicolumn{4}{|l|}{ Longitudinal axis } \\
\hline Strain (\%) & $-20.6(2.4)$ & $-19.3(2.9)$ & $-15.7(3.4)^{* * \# \# \#}$ \\
\hline Diastolic SR $\left(\% \cdot \sec ^{-1}\right)$ & $1.5(0.3)$ & $1.3(0.3)$ & $1.1(0.2)^{* * * \#}$ \\
\hline Systolic SR $\left(\% \cdot \mathrm{sec}^{-1}\right)$ & $-1.0(0.2)$ & $-1.0(0.2)$ & $-0.9(0.2)$ \\
\hline \multicolumn{4}{|l|}{ Base circumferential } \\
\hline Strain (\%) & $-16.5(3.7)$ & $-16.8(5.9)$ & $-15.8(2.6)$ \\
\hline Diastolic SR $\left(\% \cdot \sec ^{-1}\right)$ & $1.5(0.3)$ & $1.6(0.4)$ & $1.2(0.3)$ \\
\hline Systolic SR $\left(\% \cdot \sec ^{-1}\right)$ & $-1.0(0.2)$ & $-1.1(0.3)$ & $-1.1(0.3)$ \\
\hline \multicolumn{4}{|l|}{ Apex circumferential } \\
\hline Strain (\%) & $-21.4(2.7)$ & $-26.0(5.8)^{*}$ & $-26.8(3.0)^{*}$ \\
\hline Diastolic SR $\left(\% \cdot \sec ^{-1}\right)$ & $1.8(0.3)$ & $2.2(0.9)$ & $2.0(0.4)$ \\
\hline Systolic SR $\left(\% \cdot \sec ^{-1}\right)$ & $-1.2(0.2)$ & $-1.5(0.3)^{*}$ & $-1.7(0.3)^{*}$ \\
\hline \multicolumn{4}{|l|}{ Rotational mechanics } \\
\hline Apical rotation $\left(^{\circ}\right)$ & $4.1(2.1)$ & $6.4(2.2)^{*}$ & $6.1(2.1)^{*}$ \\
\hline Basal rotation $\left(^{\circ}\right)$ & $-4.6(1.6)$ & $-5.5(2.5)$ & $-6.4(3.1)$ \\
\hline Peak twist $\left({ }^{\circ}\right)$ & $6.6(2.2)$ & $8.1(3.6)$ & $11.6(2.1)^{*}$ \\
\hline Peak untwist-rate $\left({ }^{\circ} \cdot \sec ^{-1}\right)$ & $-65.0(19.5)$ & $-82.9(16.0)$ & $-92.4(22.1)^{*}$ \\
\hline
\end{tabular}

Data are means (standard deviations). SR: Strain rate. *: $p<0.05$ vs. Young; ***: $p<0.001$ vs. Young; \#: $p<0.05$ vs. Middle; \#\#: $p<0.001$ vs. Middle.

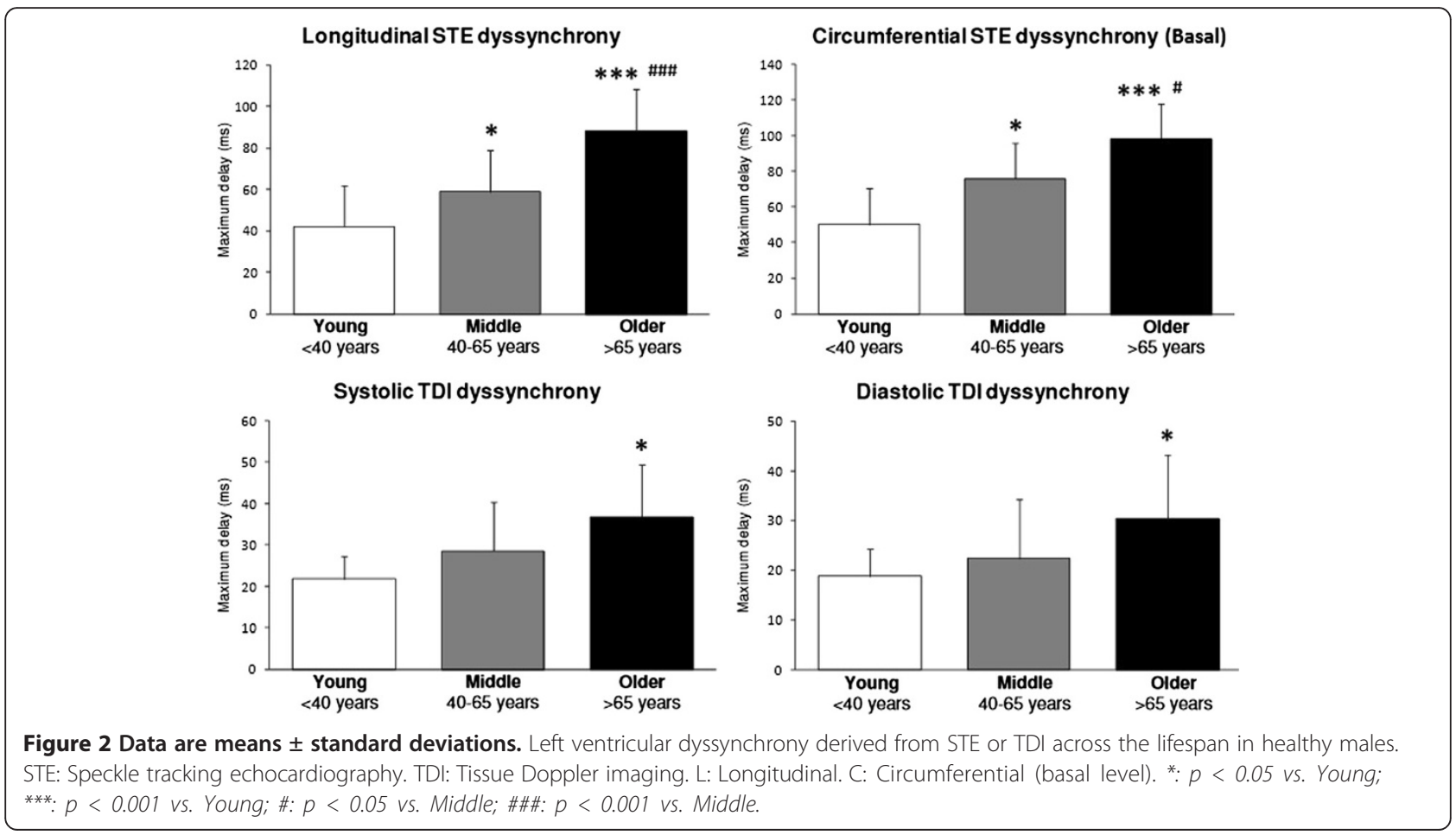


derived EAT is consistently and strongly associated with myocardial lipid content $[15,43]$. Previous autopsy findings have demonstrated that increasing levels of myocardial lipids is part of the normal aging process [44]. As lipid infiltration into the myocardium increases, LV myocardial function (such as longitudinal strain) is impaired [14,34]. In the present study, we found that increased thickness of EAT was associated with declining systolic and diastolic indices of LV myocardial mechanics. While the exact mechanisms through which EAT impacts myocardial mechanics are still speculative, early findings suggest that lipid accumulation in the epicardium causes enlargement of cardiomyocytes and thus impaired oxygen delivery. In turn, the lipid accumulation and hypoxia trigger several potential responses including: pro-inflammatory and proatherogenic cytokines in the myocardium, cardiomyocyte excitation-contraction coupling abnormalities from altered calcium handling, and increased levels of oxidative stress from reactive oxygen species [45-47]. Thus, through a series of cellular pathways, these reactive oxygen species expedite interstitial and peri-vascular fibrosis in the aging heart [48], further impairing myocardial mechanics.

\section{Aging and left ventricular dyssynchrony}

Elevated levels of fibrosis and lipid content in the more mature myocardium may also slow signal conduction [48], consequently leading to LV-dyssynchrony. The second major novel finding in the current study was that longitudinal and circumferential LV-dyssynchrony at the base increased across the age-groups, independent of the effects of cholesterol, glucose, and hsCRP. Meanwhile, circumferential LV-dyssynchrony at the apex remained unchanged. Interestingly, we found age-related increases in apical circumferential strain and rotation, but no change in basal circumferential strain or rotation. This finding agrees with previous observations of the aging-heart [10]. Thus, the potential preservation of LV pump function may be predominantly governed by apical LV function, which is more resilient to LV-dyssynchrony, and augments deformation and rotation; leading to the aforementioned compensatory increase in LV twist.

\section{Associations between LV-dyssynchrony, myocardial fat, and myocardial mechanics}

LV-dyssynchrony and EAT may be underlying factors responsible for altered myocardial mechanics in older healthy males. Only two MRI studies have observed increasing myocardial dyssynchrony in healthy aging people $[17,18]$, while no studies have previously examined agerelated changes in EAT in healthy males. We found the combination of EAT, longitudinal, and circumferential LVdyssynchrony at the base explained more than one-third of the variability in longitudinal strain and LV twist, respectively. LV-dyssynchrony and EAT may therefore be valuable early indicators of LV dysfunction in healthy older people.

\section{Clinical significance}

The potential effect of age on dyssynchrony may permit clinicians to accept a certain 'normal' level of LV-dyssynchrony in healthy older people. In the present study, half of the healthy older participants reached clinical threshold values for both longitudinal and circumferential STE dyssynchrony $[25,26]$, despite our confirmation of preserved global systolic function across the age-groups [37]. Further research may be necessary to identify age-sensitive threshold values for LV-dyssynchrony.

\section{Study limitations}

The cross-sectional design has limitations. While the number of participants in our study may appear limited, our sample size was carefully estimated and reached significance between groups. The discarding of some poor quality cine-loops, inherent to echocardiography, was a limitation; with a standard percentage of rejection [23], despite infrequent reporting in the literature $[8,28]$. A lack of echogenicity (clarity of acoustic ultrasound windows) in older participants precluded the capacity to confidently assess STE parameters in the radial axis and apical two-chamber and three-chamber windows. Intra and inter-observer variability was slightly high for twisting mechanics and LVdyssynchrony, but not dissimilar to other studies reporting these variables [49]. However, the accuracy of assessing LV-dyssynchrony was increased by the use of several techniques (TDI, STE). Biological assessments were delimited to the most clinically important parameters. Thus, understanding the aging-heart may warrant further more comprehensive investigations, including larger scale longitudinal assessment of individuals as they age.

\section{Conclusion}

We established a broad cardiac profile in healthy males of three different age-categories: demonstrating a likely age-associated decline in diastolic function and longitudinal deformation, with a compensatory increase in apical circumferential deformation, rotation and LV twist. For the first time with echocardiography, we showed increasing EAT, longitudinal, and circumferential-basal LV-dyssynchrony across three incremental age-groups of healthy males, independent of the effects of blood biology. We found these variables together significantly explained the variability in longitudinal deformation and LV twist (two major markers of LV mechanics), possibly through pro-inflammatory and pro-fibrotic pathways in the myocardium. Understanding the healthy aging-heart and its typical evolution may assist in the early distinction and prevention of cardiovascular diseases in healthy aging people. 


\section{Competing interests}

The authors declare that they have no competing interests.

\section{Authors' contributions}

TM, GN, and EC recruited participants. EC conducted all echocardiographic and clinical measurements. GN, FD and EC conducted statistical analyses. FD and EC drafted the paper, and GN and PO reviewed, corrected and helped finalise the manuscript. All authors read and approved the final manuscript.

\section{Acknowledgements}

We thank the volunteers who participated in this study, particularly the very elderly gentlemen from the Narrabeen War Veterans Village who kindly donated their time and interest to this research.

\section{Funding}

This research received no specific grant from any funding agency in the public, commercial or not-for-profit sectors.

\section{Author details}

'School of Exercise Science, Australian Catholic University, Locked Bag 4115, Fitzroy, MDC Victoria 3065, Australia. 'Laboratory of Pharm-Ecology Cardiovascular EA4278, School of Sport Sciences and Exercise, University of Avignon, Avignon, France. ${ }^{3}$ Laboratory of Metabolic Adaptations to Exercise in Physiological and Pathological conditions EA3533, Blaise Pascal University Clermont-Ferrand, France. ${ }^{4}$ Occupational Medicine, University Hospital CHU G. Montpied, Clermont-Ferrand, France.

\section{Received: 27 May 2014 Accepted: 23 July 2014}

Published: 3 August 2014

\section{References}

1. Report of the world health organization. Active ageing: a policy framework. Aging Male 2002, 5(1):1-37.

2. World health organization launches new initiative to address the health needs of a rapidly ageing population. Cent Eur J Public Health 2004, 12(4):210-216

3. Kelly BB, Narula J, Fuster V: Recognizing global burden of cardiovascular disease and related chronic diseases. Mt Sinai J Med 2012, 79(6):632-640

4. Cheitlin MD: Cardiovascular physiology-changes with aging. Am J Geriatr Cardiol 2003, 12(1):9-13.

5. Lakatta EG: Age-associated cardiovascular changes in health: impact on cardiovascular disease in older persons. Heart Fail Rev 2002, 7(1):29-49.

6. Ribera-Casado JM: Ageing and the cardiovascular system. Z Gerontol Geriatr 1999, 32(6):412-419.

7. Dandel M, Lehmkuhl H, Knosalla C, Suramelashvili N, Hetzer R: Strain and strain rate imaging by echocardiography - basic concepts and clinical applicability. Curr Cardiol Rev 2009, 5(2):133-148.

8. Sun JP, Lam YY, Wu CQ, Yang XS, Guo R, Kwong JS, Merlino JD, Yu CM: Effect of age and gender on left ventricular rotation and twist in a large group of normal adults - A multicenter study. Int I Cardiol 2013, 167(5):2215-2221.

9. Takeuchi M, Nakai H, Kokumai M, Nishikage T, Otani S, Lang RM: Age-related changes in left ventricular twist assessed by two-dimensional speckle-tracking imaging. J Am Soc Echocardiogr 2006, 19(9):1077-1084.

10. van Dalen BM, Soliman OI, Vletter WB, ten Cate FJ, Geleijnse ML: Age-related changes in the biomechanics of left ventricular twist measured by speckle tracking echocardiography. Am J Physiol Heart Circ Physiol 2008, 295(4):22.

11. Zghal F, Bougteb H, Reant P, Lafitte S, Roudaut R: Assessing global and regional left ventricular myocardial function in elderly patients using the bidimensional strain method. Echocardiography 2011, 28(9):978-982.

12. Zhang $L$, Xie M, Fu M: Assessment of age-related changes in left ventricular twist by two-dimensional ultrasound speckle tracking imaging. J Huazhong Univ Sci Technolog Med Sci 2007, 27(6):691-695.

13. Kaku K, Takeuchi M, Tsang W, Takigiku K, Yasukochi S, Patel AR, Mor-Avi V, Lang RM, Otsuji Y: Age-related normal range of left ventricular strain and torsion using three-dimensional speckle-tracking echocardiography. J Am Soc Echocardiogr 2014, 27(1):55-64.

14. Kankaanpaa M, Lehto HR, Parkka JP, Komu M, Viljanen A, Ferrannini E, Knuuti J, Nuutila P, Parkkola R, lozzo P: Myocardial triglyceride content and epicardial fat mass in human obesity: relationship to left ventricular function and serum free fatty acid levels. J Clin Endocrinol Metab 2006, 91(11):4689-4695.

15. Malavazos AE, Di Leo G, Secchi F, Lupo EN, Dogliotti G, Coman C, Morricone L, Corsi MM, Sardanelli F, lacobellis G: Relation of echocardiographic epicardial fat thickness and myocardial fat. Am J Cardiol 2010, 105(12):1831-1835.

16. Abraham TP, Lardo AC, Kass DA: Myocardial dyssynchrony and resynchronization. Heart Fail Clin 2006, 2(2):179-192.

17. Rosen BD, Fernandes VR, Nasir K, Helle-Valle T, Jerosch-Herold M, Bluemke DA, Lima JA: Age, increased left ventricular mass, and lower regional myocardial perfusion are related to greater extent of myocardial dyssynchrony in asymptomatic individuals: the multi-ethnic study of atherosclerosis. Circulation 2009, 120(10):859-866.

18. Foll D, Jung B, Germann E, Hennig J, Bode C, Markl M: Magnetic resonance tissue phase mapping: analysis of age-related and pathologically altered left ventricular radial and long-axis dyssynchrony. J Magn Reson Imaging 2011, 34(3):518-525

19. Hurtig-Wennlof A, Hagstromer M, Olsson LA: The International Physical Activity Questionnaire modified for the elderly: aspects of validity and feasibility. Public Health Nutr 2010, 13(11):1847-1854.

20. Sahn DJ, DeMaria A, Kisslo J, Weyman A: Recommendations regarding quantitation in M-mode echocardiography: results of a survey of echocardiographic measurements. Circulation 1978, 58(6):1072-1083.

21. de Simone G, Daniels SR, Devereux RB, Meyer RA, Roman MJ, de Divitiis O, Alderman MH: Left ventricular mass and body size in normotensive children and adults: assessment of allometric relations and impact of overweight. J Am Coll Cardiol 1992, 20(5):1251-1260.

22. lacobellis G, Assael F, Ribaudo MC, Zappaterreno A, Alessi G, Di Mario U, Leonetti F: Epicardial fat from echocardiography: a new method for visceral adipose tissue prediction. Obes Res 2003, 11(2):304-310.

23. Obert P, Gueugnon C, Nottin S, Vinet A, Gayrard S, Rupp T, Dumoulin G, Tordi N, Mougin F: Two-dimensional strain and twist by vector velocity imaging in adolescents with severe obesity. Obesity (Silver Spring) 2012, 20(12):2397-2405.

24. Risum N, Williams ES, Khouri MG, Jackson KP, Olsen NT, Jons C, Storm KS, Velazquez EJ, Kisslo J, Bruun NE, Sogaard P: Mechanical dyssynchrony evaluated by tissue Doppler cross-correlation analysis is associated with long-term survival in patients after cardiac resynchronization therapy. Eur Heart J 2013, 34(1):48-56.

25. Zhang Q, van Bommel RJ, Fung JW, Chan JY, Bleeker GB, Ypenburg C, Yip G, Liang YJ, Schalij MJ, Bax JJ, Yu CM: Tissue Doppler velocity is superior to strain imaging in predicting long-term cardiovascular events after cardiac resynchronisation therapy. Heart 2009, 95(13):1085-1090.

26. Purushottam B, Parameswaran AC, Figueredo VM: Dyssynchrony in obese subjects without a history of cardiac disease using velocity vector imaging. J Am Soc Echocardiogr 2011, 24(1):98-106.

27. Gravetter F, Wallnau L: Essentials of Statistics for the Behavioral Sciences. 8th edition. South Melbourne, Australia: Cengage Learning; 2013.

28. van Dalen BM, Soliman OI, Kauer F, Vletter WB, Zwaan HB, Cate FJ, Geleijnse ML: Alterations in left ventricular untwisting with ageing. Circ J 2010, 74(1):101-108.

29. Olivetti G, Giordano G, Corradi D, Melissari M, Lagrasta C, Gambert SR, Anversa P: Gender differences and aging: effects on the human heart. J Am Coll Cardiol 1995, 26(4):1068-1079.

30. Nikitin NP, Loh PH, de Silva R, Witte KK, Lukaschuk El, Parker A, Farnsworth TA, Alamgir FM, Clark AL, Cleland JG: Left ventricular morphology, global and longitudinal function in normal older individuals: a cardiac magnetic resonance study. Int J Cardiol 2006, 108(1):76-83.

31. Lakatta EG, Levy D: Arterial and cardiac aging: major shareholders in cardiovascular disease enterprises: Part II: the aging heart in health: links to heart disease. Circulation 2003, 107(2):346-354.

32. Cacciapuoti F, Marfella R, Paolisso G: Is the aging heart similar to the diabetic heart? Evaluation of LV function of the aging heart with Tissue Doppler Imaging. Aging Clin Exp Res 2009, 21(1):22-26.

33. Gruner Svealv B, Fritzon G, Andersson B: Gender and age related differences in left ventricular function and geometry with focus on the long axis. Eur J Echocardiogr 2006, 7(4):298-307.

34. van der Meer RW, Rijzewijk LJ, Diamant M, Hammer S, Schar M, Bax JJ, Smit JW, Romijn JA, de Roos A, Lamb HJ: The ageing male heart: myocardial triglyceride content as independent predictor of diastolic function. Eur Heart J 2008, 29(12):1516-1522. 
35. Yamada H, Oki T, Mishiro Y, Tabata T, Abe M, Onose Y, Wakatsuki T, Ito S: Effect of aging on diastolic left ventricular myocardial velocities measured by pulsed tissue Doppler imaging in healthy subjects. J Am Soc Echocardiogr 1999, 12(7):574-581.

36. Henein $M$, Lindqvist $P$, Francis $D$, Morner $S$, Waldenstrom A, Kazzam E: Tissue Doppler analysis of age-dependency in diastolic ventricular behaviour and filling: a cross-sectional study of healthy hearts (the Umea General Population Heart Study). Eur Heart J 2002, 23(2):162-171.

37. Ruan Q, Nagueh SF: Effect of age on left ventricular systolic function in humans: a study of systolic isovolumic acceleration rate. Exp Physiol 2005, 90(4):527-534.

38. Onose Y, Oki T, Mishiro Y, Yamada H, Abe M, Manabe K, Kageji Y, Tabata T, Wakatsuki T, Ito $S$ : Influence of aging on systolic left ventricular wall motion velocities along the long and short axes in clinically normal patients determined by pulsed tissue doppler imaging. J Am Soc Echocardiogr 1999, 12(11):921-926.

39. Yip GW, Zhang Y, Tan PY, Wang M, Ho PY, Brodin LA, Sanderson JE: Left ventricular long-axis changes in early diastole and systole: impact of systolic function on diastole. Clin Sci (Lond) 2002, 102(5):515-522.

40. Oki T, Fukuda K, Tabata T, Mishiro Y, Yamada H, Abe M, Onose Y, Wakatsuki $\mathrm{T}$, luchi $\mathrm{A}$, Ito $\mathrm{S}$ : Effect of an acute increase in afterload on left ventricular regional wall motion velocity in healthy subjects. $J$ Am Soc Echocardiogr 1999, 12(6):476-483.

41. Sun JP, Popovic ZB, Greenberg NL, Xu XF, Asher CR, Stewart WJ, Thomas JD: Noninvasive quantification of regional myocardial function using Doppler-derived velocity, displacement, strain rate, and strain in healthy volunteers: effects of aging. J Am Soc Echocardiogr 2004, 17(2):132-138.

42. Kuznetsova T, Herbots L, Richart T, D'Hooge J, Thijs L, Fagard RH, Herregods $M C$, Staessen JA: Left ventricular strain and strain rate in a general population. Eur Heart J 2008, 29(16):2014-2023.

43. Sai E, Shimada K, Yokoyama T, Sato S, Miyazaki T, Hiki M, Tamura Y, Aoki S, Watada H, Kawamori R, Daida H: Association between myocardial triglyceride content and cardiac function in healthy subjects and endurance athletes. PLoS One 2013, 8(4):e61604.

44. Tansey DK, Aly Z, Sheppard MN: Fat in the right ventricle of the normal heart. Histopathology 2005, 46(1):98-104.

45. Guzzardi MA, lozzo P: Fatty heart, cardiac damage, and inflammation. Rev Diabet Stud 2011, 8(3):403-417.

46. Hosogai N, Fukuhara A, Oshima K, Miyata Y, Tanaka S, Segawa K, Furukawa S, Tochino Y, Komuro R, Matsuda M, Shimomura I: Adipose tissue hypoxia in obesity and its impact on adipocytokine dysregulation. Diabetes 2007 56(4):901-911.

47. Ouwens DM, Diamant M, Fodor M, Habets DD, Pelsers MM, El Hasnaoui M, Dang ZC, van den Brom CE, Vlasblom R, Rietdijk A, Boer C, Coort SL, Glatz $J F$, Luiken JJ: Cardiac contractile dysfunction in insulin-resistant rats fed a high-fat diet is associated with elevated CD36-mediated fatty acid uptake and esterification. Diabetologia 2007, 50(9):1938-1948.

48. Biernacka A, Frangogiannis NG: Aging and Cardiac Fibrosis. Aging Dis 2011, 2(2):158-173.

49. Schuster I, Vinet A, Karpoff L, Startun A, Jourdan N, Dauzat M, Nottin S, Perez-Martin A: Diastolic dysfunction and intraventricular dyssynchrony are restored by low intensity exercise training in obese men. Obesity (Silver Spring) 2012, 20(1):134-140.

\section{doi:10.1186/1471-2261-14-95}

Cite this article as: Crendal et al:: Increased myocardial dysfunction dyssynchrony, and epicardial fat across the lifespan in healthy males. BMC Cardiovascular Disorders 2014 14:95.

\section{Submit your next manuscript to BioMed Central and take full advantage of:}

- Convenient online submission

- Thorough peer review

- No space constraints or color figure charges

- Immediate publication on acceptance

- Inclusion in PubMed, CAS, Scopus and Google Scholar

- Research which is freely available for redistribution 